\title{
The Carbon Footprint of an East African Forestry Enterprise
}

\author{
Jacopo Parigiani \\ Green Resources Ltd. PO Box 55, Mafinga, Tanzania \\ Tel: 255-654-122-183Ｅ-mail: jacopo.parigiani@greenresources.no \\ Aman Desai \\ 350 Jesse Street, Sebastopol, California 95472, USA \\ Tel: 1-707-486-0752 E-mail: aman.g.desai@gmail.com \\ Roselyne Mariki \\ Green Resources Ltd. \\ Mwalimu House, PO Box 4730, Dar Es Salaam, Tanzania \\ Tel: 255-784-492-556 \\ Reid Miner (Corresponding author) \\ NCASI \\ PO Box 13318, Research Triangle Park, NC 27709 USA \\ Tel: 1-919-941-6407Ｅ-mail: rminer@ncasi.org
}

Received: February 22, 2011

Accepted: March 31, 2011

doi:10.5539/jsd.v4n3p152

This work was financed, in part, by International Finance Corporation (IFC) of the World Bank Group and the Government of Finland

\begin{abstract}
Green Resources AS, a plantation, carbon offset, forest products, and renewable energy company with operations in Eastern Africa, calculated carbon footprints for 2008 and 2009. In both years, the footprint was dominated by removals of $\mathrm{CO}_{2}$ from the atmosphere attributable to afforestation. These removals were more than 17 times the emissions from the company's value chain. The largest difference between the 2008 and 2009 footprints was due to loss of forest carbon caused by fire. Otherwise, the most important changes in the footprint were related to plantation expansion and growth, and increased output of products in 2009, which caused increases in several types of emissions. The remaining elements of the footprint (manufacturing, forestry operations, transport, and upstream emissions related to non-fibrous inputs, fuels, and electricity) were approximately equal. The use of the charcoal manufactured by the company avoided coal-related emissions equal to approximately one-quarter of the company's value chain emissions.
\end{abstract}

Keywords: Afforestation, Carbon footprint, Africa, Greenhouse gas, Plantation, FICAT

\section{Introduction}

Recent years have seen increasing efforts to understand the implications of products, activities, and policies on atmospheric greenhouse gases. One important tool in these efforts has been life cycle assessment (LCA), or more specifically the carbon footprint, which is an estimate of the life cycle impacts of a product or activity on atmospheric greenhouse gases. A wide range of forest products have been examined in LCA and carbon footprint studies, ranging from materials used in home construction (e.g., see Salazar \& Sowlati, 2008; Perez-Garcia, Lippke, Comnick \& Manriquez, 2005; Gustavsson \& Sathre, 2006) to biofuels (e.g. ,see Cherubini et al., 2009). Several industry-wide carbon footprint studies have also been performed on the forest products industry (e.g., see Miner, 2010 and Heath et al., 2010). Recently, companies have begun attempts to understand 
their corporate carbon footprints. Under the Carbon Disclosure Project, for instance, 57 companies, including at least one forest products company, have expanded their reporting from manufacturing-related emissions to include a variety of other "supply chain" emissions (Carbon Disclosure Project [CDP], 2011). Few corporate carbon footprint studies, however, have been published in the literature.

Green Resources AS is a plantation, carbon offset, forest products, and renewable energy company. The company operates in Tanzania, Uganda, Mozambique, and Southern Sudan, and has offices in London and headquarters in Lysaker, Norway (Green Resources [GRAS], 2011). Being involved in carbon offset programs and in the generation of renewable energy, the company determined that it was important to understand the carbon footprint of all its operations in order to identify opportunities for improvement in its corporate carbon footprint. The company also desired to analyze year-to-year trends in the company's carbon footprint as this would provide a measure of success and would be helpful in both internal and external discussions about the company's sustainability performance.

Furthermore, Green Resources AS is striving to be an innovator within East Africa, as illustrated by its being the first company in Tanzania to do a carbon footprint. In this regard, the company played an active role in determining the carbon footprint procedures and methodologies which were proposed by the national standards body, the TBS (Tanzania Body of Standards), to the International Organization for Standardization (ISO) for consideration in the development of international carbon footprint standards.

Green Resources AS has more than 14,000 ha of new forest. It is growing trees to generate carbon credits and bio-energy and to manufacture wood products. The company's plantations, which first produced wood in 2008, are being expanded at the rate of approximately 4,000 hectares per year (GRAS 2011). As the company's planted forests are maturing, wood is currently mainly sourced from plantation forests established in the Southern Highlands of Tanzania by the Tanzanian government in the 1970s. Green Resources' industrial operation, Sao Hill Industries, is East Africa's largest sawmill and one of the largest transmission pole producers in the region; it also owns small carpentry and joinery plants.

It is the aim of Green Resources AS to have all its forests certified according to the Forest Stewardship Council's standards. The company harvests only plantation forest and only plants on grassland or degraded forestland. It focuses on a wide variety of species, including pine, eucalyptus, teak, measopsis and various indigenous trees.

One of the investors in Green Resources AS is the International Finance Corporation (IFC), the private sector arm of the World Bank Group. In 2009, Green Resources AS and IFC undertook a study to determine the company's 2008 carbon footprint. The carbon footprint study was repeated in 2009 to identify important changes in the footprint between 2008 and 2009. This paper describes the methods and findings from these carbon footprint studies.

\section{Methods}

The company's carbon footprint was developed using the Forest Industry Carbon Assessment Tool (FICAT) (International Finance Corporation [IFC]/National Council for Air and Stream Improvement [NCASI], 2009). FICAT uses life cycle concepts to examine the carbon and greenhouse gas impacts of forest-based operations from cradle-to-grave. The tool is structured along the lines of the 10-element Framework for the Development of Carbon Footprints for Paper and Board Products developed by the Confederation of European Paper Industries [CEPI], 2007). The 10 elements in the framework and the basic calculation methods are listed below. More detailed information on the calculations methods and assumptions is available in the online documentation for FICAT (NCASI, 2009). In Table 1, the relevant activities of Green Resources AS are listed for each of the ten elements of the footprint.

[Insert Table 1]

\subsection{Carbon in Forest Ecosystems}

FICAT uses stock change accounting to calculate the net transfers of biomass carbon to or from the atmosphere. Under stock change accounting, net transfers of biomass carbon to the atmosphere are determined by summing all of the changes in stocks of stored biomass carbon along the value chain, i.e., in carbon stored in forests, products-in-use, and products-in-landfills.

FICAT calculates a change in carbon stocks on the area of land supplying wood to, or impacted by, an entity. The user must define the area or areas and the period over which the stock changes are determined or averaged. FICAT is pre-populated with default carbon stock values from the Tier 1 methodology in the national greenhouse gas inventory guidelines published by the Intergovernmental Panel on Climate Change (IPCC) (International Panel on Climate Change, 2006). FICAT, however, allows the user to override the IPCC defaults. 
For the plantations owned by Green Resources AS, the calculations for forest carbon were based on stock changes estimated from site-specific modeling and on-the-ground surveys. The results reflect the annualized long-term impact of converting grasslands to plantation forest. The calculations are based on the specific growth rates and rotation lengths for the species being planted. The carbon losses due to major fires in 2009 were based on surveys and company calculations. The land managed by Green Resources AS includes areas under company control that, as of the dates of the inventories, had not yet been influenced by the company's activities. The stock changes on these lands were assumed to be zero, although it is likely that carbon stocks were increasing on some of these lands.

Where wood is obtained from Tanzania government-owned forest, the carbon stocks are expected to return to pre-harvest levels, so in FICAT, the annualized long-term impact on land-based carbon stocks is entered as zero.

\subsection{Carbon in Forest Products}

A portion of the carbon removed from the forest during harvest may be transferred into products where it is stored for periods varying from days to decades or longer, depending on the product. The carbon in products is stored in two "pools": products-in-use and products-in-landfills.

FICAT uses the "100-year method" to estimate the significance of carbon stored in products-in-use (Miner, 2006). This method uses IPCC calculations methods to estimate the fraction of carbon in a product that will, on average, remain in use for at least 100 years. The parameter values are from IPCC's 2006 Guidelines for National Greenhouse Gas Inventory (IPCC, 2006) and other published sources, but the user may override these default values where more appropriate values exist. The carbon that does not remain in use is assumed to go to end-of-life. The amount of non-degradable biomass carbon expected to remain in landfills is calculated from data and methods in IPCC's 2006 Guidelines for National Greenhouse Gas Inventories (IPCC, 2006) and the third edition of USEPA's Solid Waste Management and Greenhouse Gases: A Life-Cycle Assessment of Emissions and Sinks (United States Environmental Protection Agency [USEPA], 2006).

In the carbon footprint study for Green Resources AS, the data used to estimate carbon storage in products-in-use came from a combination of internal company sources (e.g., production information), FICAT defaults, and best professional estimates. In the experience of the authors, it is unlikely that forest products used in East Africa will be disposed in landfills. For this reason, the only carbon stored in products is assumed to reside in long-lived products-in-use. These long-lived products include preservative-treated poles, sawn timber (treated and untreated), and various value-added products made from timber (e.g., doors, door frames, window frames, beds, chairs, laminated sheets, pallets, and other furniture). The half-lives for products in use were assumed to be 15 years for untreated sawn wood, 20 years for carpentry products and treated poles, and 30 years for preservative-treated sawn wood.

\subsection{Greenhouse Gas Emissions from Forest Products Manufacturing Facilities}

Emissions from fuel combustion were estimated directly from fuel consumption data and FICAT default emission factors which are based on IPCC's 2006 Guidelines for National Greenhouse Gas Inventories (IPCC, 2006). The greenhouse gases included in this study were $\mathrm{CO}_{2}$, methane, and nitrous oxide. Carbon dioxide emissions from biomass combustion were accounted for in the comprehensive accounting of changes carbon stocks in forest and forest products, and therefore were not included as combustion-related emissions. Methane and nitrous oxide from biomass combustion, however, were included in emissions estimates. The global warming potentials used for $\mathrm{CH}_{4}$ and $\mathrm{N}_{2} \mathrm{O}$ were from IPCC's 2006 Guidelines for National Greenhouse Gas

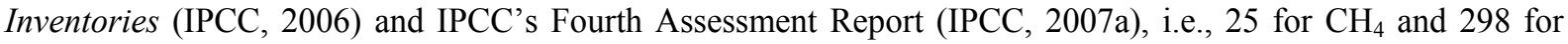
$\mathrm{N}_{2} \mathrm{O}$. Methane emissions from charcoal production were estimated using an emission factor of $47.5 \mathrm{~kg}$ methane per ton of charcoal (Clean Development Mechanism Executive Board, 2006). The heating-related emissions of the European offices were estimated based on the area of the offices and factors for heating found in USEPA (2007).

\subsection{Greenhouse Gas Emissions Associated with Producing Wood}

For the studies of Green Resources AS, forestry-related emissions due to fire and chemical use were estimated using custom emission factors developed from data and methods in IPCC's 2006 Guidelines for National Greenhouse Gas Inventories (IPCC, 2006) and public life cycle databases (Swiss Centre for Life Cycle Inventories, 2010). Emissions related to fossil fuel consumption were calculated directly from fuel consumption statistics and emission factors in FICAT. 


\subsection{Greenhouse Gas Emissions Associated with Producing Other Raw Materials/Fuels}

For the estimates prepared in this study, emission factors were developed to account for the specific chemicals used to make the company's products. These chemicals are used for treating wood (chromated copper arsenate) and manufacturing wooden doors (e.g., glues and varnishes) and other carpentry products. Emission factors for these chemicals were derived from the literature and life cycle databases (Swiss Centre for Life Cycle Inventories, 2010). Default FICAT emission factors, derived from the U.S. Life-Cycle Inventory Database, were used to estimate upstream emission associated with fossil fuels (United States Department of Energy [USDOE], 2010). All of these emissions are indirect.

\subsection{Greenhouse Gas Emissions Associated with Purchased Electricity}

Electricity purchases by the company's manufacturing operations in Tanzania were determined from company records while the purchases by other offices elsewhere were estimated from the office area and factors in USEPA (2007). The greenhouse gas intensity of electricity purchased from the grid in Tanzania (grid emission factor of 0.586 tons $\mathrm{CO}_{2}$ eq./ $\mathrm{MWh}$ ) was calculated using three-year hourly generation data from the main utility, Tanzania Electric Supply Company. The default factors in FICAT were used for the offices in Europe.

\subsection{Transport-Related Greenhouse Gas Emissions}

The value chain of Green Resources AS requires transport of raw materials and products. Because the company supplies the fuel for the vehicles that transport these materials, these emissions were estimated directly from fuel consumption. In addition, the emissions attributable to air travel by company personnel were estimated from FICAT factors, derived from calculation tools issued under the GHG Protocol World Resources Institute/World Business Council for Sustainable Development [WRI/WBCSD], 2005).

\subsection{Emissions Associated with Product Use}

The only product made by Green Resources AS which releases greenhouse gases during use is charcoal, which is produced as a fuel and sold to a nearby cement manufacturer who uses it to replace mineral coal. The burning of charcoal produces small amounts of methane and nitrous oxide. FICAT's default emission factors, which are based on IPCC's 2006 Guidelines for National Greenhouse Gas Inventories (IPCC, 2006), were used in the calculations. All of these emissions are indirect, meaning that they are from sources that are not owned or controlled by Green Resources AS.

\subsection{Emissions Associated with Product End-of-Life}

Although a forest product may be reused or disposed of in many ways, the most important end-of-life emissions are methane emissions from landfills (e.g., see Miner, 2010). FICAT estimates these based on a combination of user-entered information (the quantities and types of products and the characteristics of the landfills), and default parameters (describing product decomposition and methane release) primarily from IPCC (2006) and USEPA (2006) End-of-life emissions were not estimated in the Green Resources AS carbon footprint because it was assumed, based on best professional judgment, that all used products are recovered and used for other purposes in the markets served by Green Resources AS.

\subsection{Avoided Emissions}

FICAT assists in estimating three types of avoided emissions. Only one was estimated in the Green Resources AS carbon footprint. Avoided emissions associated with the use of biomass-based materials sold by the company as fuel are estimated in FICAT by assuming that these fuels displace fossil fuels. In this case, the energy content of charcoal (30 GJ LHV per dry ton) was from company test results and the rest of the parameter values were FICAT defaults. For information purposes, Green Resources AS also estimated the avoided emissions associated with anticipated exports of renewable energy. These are calculated in FICAT by taking the difference between the greenhouse gas intensity of exported electricity and the greenhouse gas intensity of electricity on the grid (determined as discussed above in section 2.6).

\subsection{Boundary Conditions}

The complete value chain (forest to end-of-life) was included in the studies for 2008 and 2009.

The emissions or stock changes (for biomass carbon) occurred in calendar years 2008 and 2009 with the following exceptions.

- For mature government forest that is being harvested and replanted, the impact on long-term carbon stocks is assessed over at least one full rotation. 
- Some of the upstream emissions associated with non-fiber inputs and fuels may have occurred prior to the reporting year.

- The impacts of carbon stored in products in use were estimated over a period of 100 years following production.

The specific operations included in the 2008 and 2009 footprint are the following.

- Forestry operations

○ 32,555 hectares located in the southern highlands of Tanzania, consisting of both planted forest and conservation areas

- 9,500 hectares located on the Northern coast of Tanzania

- 13,000 hectares located on the Southern coast of Tanzania

- Tree Farms in Mozambique (Sanga Forest) so far (to date) 976 hectares (total area under management is $46,000 \mathrm{ha}$ )

- Bukaleba Forest Company (Uganda) so far a total of 3,465 hectares planted (total area under GRAS management is 9,215 ha)

- NAG (Kachung Forest Project, Uganda) so far a total of 2,065 hectares planted (total area under GRAS management is $2,670 \mathrm{ha}$ )

- Tindilo Forest Project in Southern Sudan, so far 642 hectares planted (total area under GRAS management is 179,859 ha)

- Industrial operations

- Sao Hill Industries (SHI) Ltd., producing charcoal, sawn timber, transmission poles, and value-added products (such as furniture and pallets)

- Sao Hill Transport (SHT) Ltd., involved in the company's transport operations including delivery of transmission poles, value-added products, and sawn timber.

- Office operations

- Office operations in Oslo, Norway; London, UK; Tanzania, Uganda, and Mozambique (if these were also included) and Dar es Salaam, Tanzania. Air travel by company staff was also included in the calculations.

\section{Results}

\subsection{Carbon in Forest Ecosystems}

The quantity of carbon stored in company forests increased by 125,000 tons of $\mathrm{CO}_{2}$ equivalents in 2008 . The amounts added to forest carbon stocks in 2009 were slightly larger: 132,000 tons of $\mathrm{CO}_{2}$ equivalents. These large removals of $\mathrm{CO}_{2}$ from the atmosphere were due to the planting of new forests and growth of forests planted in earlier years.

In spite of fires in 2009, gains in forest carbon stocks were greater in 2009 than in 2008. A no-fire scenario was run in FICAT to calculate the impacts of the 2009 fires. The results indicate that net carbon sequestration in the forest in 2009 would have been $37 \%$ larger were it not for the impact of the fires.

\subsection{Carbon in Forest Products}

The long-lived products manufactured by Green Resources AS include preservative-treated poles, sawn timber (with and without preservative treatment), and a number of carpentry products (e.g., doors, door frames, window frames, beds, chairs, laminated sheets, pallets, and other furniture). The amount of carbon in the company's products expected to remain in long-term storage (for at least 100 years) increased from 2003 tons of $\mathrm{CO}_{2}$ equivalents in 2008 to 2,260 tons in 2009. The carbon stored in products was higher in 2009, primarily due to higher production of preservative-treated transmission poles in 2009.

\subsection{Greenhouse Gas Emissions from Forest Products Manufacturing Facilities}

Because all of the manufacturing operations in the study are owned by Green Resources AS, all of the manufacturing-related emissions are direct emissions. Manufacturing-related emissions increased from 1,068 tons of $\mathrm{CO}_{2}$ equivalents in 2008 to 2,118 tons of $\mathrm{CO}_{2}$ equivalents in 2009. The largest contributor to the increase in emissions between 2008 and 2009 was charcoal production, which grew by more than $800 \%$ between 2008 and 2009 (from 97 tons in 2008 to 834 tons in 2009). 


\subsection{Greenhouse Gas Emissions Associated with Producing Wood}

Three types of emissions associated with wood production were estimated in this study: fossil fuel-related combustion emissions, emissions associated with the production and use of chemicals used in forestry, and emissions due to fire. Emissions related to fossil fuel consumption are direct emissions while the remaining emissions are indirect. The most important sources of emissions were associated with (a) the use of fire in government-owned forests, where fire is used to prepare the sites for planting, and (b) upstream emissions and emissions during use related to fertilizers, hydrogels, and other chemicals used in newly planted areas. The emissions associated with wood production were lower in 2009 than in 2008 , falling to 1,918 tons $\mathrm{CO}_{2}$ equivalents from 2,044 tons $\mathrm{CO}_{2}$ equivalents in 2009. The decrease was due to less area being treated using fire in 2009 on Tanzania government forest, made possible by an increased in harvested area in Green Resources AS plantations.

\subsection{Greenhouse Gas Emissions Associated with Producing Other Raw Materials/Fuels}

These emissions include upstream emissions associated with producing fossil fuels as well as chemicals used in manufacturing (e.g., chromated copper arsenate, glues, and varnishes). Approximately one-half of these emissions are attributable to chemicals used in manufacturing. Emissions attributable to fossil fuels and non-fiber inputs to manufacturing increased from 832 tons of $\mathrm{CO}_{2}$ equivalents in 2008 to 1,170 tons of $\mathrm{CO}_{2}$ equivalents in 2009 due to increased production.

\subsection{Greenhouse Gas Emissions Associated with Purchased Electricity}

Electricity purchases were relatively constant between 2008 and 2009, so there is very little difference in the emissions for these two years $\left(1,025\right.$ tons of $\mathrm{CO}_{2}$ equivalents in 2008 compared to 1,033 tons of $\mathrm{CO}_{2}$ equivalents in 2009). All of these emissions are indirect.

\subsection{Transport-Related Greenhouse Gas Emissions}

Transport-related emissions were calculated for raw materials, products and employee travel. Because some of the transport operations are owned by Green Resources AS, the emissions in Element 7 consist of both direct and indirect emissions. The increase in emissions, from 1,002 tons of $\mathrm{CO}_{2}$ equivalents in 2008 to 1,391 tons of $\mathrm{CO}_{2}$ equivalents in 2009, was attributable to increased production of end user products resulting in an increase in the transport of products.

\subsection{Emissions Associated with Product Use}

Green Resources AS produces charcoal which is used as a fuel by a nearby cement manufacturer. The combustion of the charcoal releases small amounts of methane and nitrous oxide, which are included in the Green Resources AS footprint. These emissions, which comprise only a small part of the Green Resources AS carbon footprint, were 25 tons of $\mathrm{CO}_{2}$ equivalents in 2009. These emissions were higher than those in 2008 (3 tons of $\mathrm{CO}_{2}$ equivalents) due to a more than 8 -fold increase in charcoal production.

\subsection{Emissions Associated with Product End-of-Life}

Given common practice in East Africa, it is assumed that products from Green Resources' value chain are reused for other purposes after having served their primary function rather than being disposed of. These subsequent uses are not considered part of the Green Resources AS footprint. In addition, the company landfills no manufacturing wastes. As a result, there are no emissions associated with end-of-life in Green Resources' footprint.

\subsection{Avoided Emissions}

In this study, the only avoided emissions that have been attributed to the activities or products of Green Resources AS are those related to the use of charcoal, produced by the company, in a cement factory which substitutes the charcoal for coal. The avoided emissions in 2009 (1,821 tons of $\mathrm{CO}_{2}$ equivalents) are much larger than in 2008 ( 212 tons of $\mathrm{CO}_{2}$ equivalents) due to the increase in charcoal production between 2008 and 2009.

\section{Discussion}

The complete carbon footprints of Green Resources AS for 2008 and 2009 are shown in Table 2. In both years, the carbon footprint of Green Resources AS is dominated by the company's afforestation activities. In both 2008 and 2009, the growth of carbon stocks in Green Resources' plantations was the equivalent of removing about 130,000 tons of $\mathrm{CO}_{2}$ from the atmosphere. The benefits for 2009 would have been approximately 50,000 tons of $\mathrm{CO}_{2}$ larger were it not for fires in some of the company's Tanzania plantations in 2009. Even after these losses, afforestation-related sequestration is over 17 times the emissions from the company's value chain. 


\section{[Insert Table 2]}

The wood products manufactured by the company store large amounts of carbon during use; enough to offset approximately one-quarter to one-third of the emissions from the value chain. The value chain emissions consist of a number of different elements of generally similar importance. These elements are (a) manufacturing emissions, (b) emissions related to wood production (related to burning in government plantations and chemical use in Green Resources' plantations), (c) upstream emissions attributable to non-fibrous inputs and fuels, (d) emissions related to purchased electricity, and (e) transport-related emissions. The use of the charcoal, manufactured by Green Resources AS from sustainably produced wood, avoids coal-related emissions equal to approximately one-quarter of the company's value chain emissions.

The most important changes in the footprint from 2008 to 2009 were related to plantation expansion and growth (even considering the losses of forest carbon due to 2009 fires) and increased output of products in 2009, which caused increases in emissions along the value chain. The losses of biomass carbon due to fire overwhelmed the other changes in emissions in the company's value chain between 2008 and 2009, being over 6 times the combined 2009 emissions from the value chain.

Table 3 demonstrates that the carbon footprint of Green Resources AS is very different from the footprint of the global forest industry (Miner, 2010). This is primarily due to the overwhelming influence of afforestation activities on Green Resources' footprint. At the global level, afforestation activities are a relatively small part of the industry's activities in the forest. In addition, the manufacturing processes used by Green Resources AS do not include paper manufacturing, which is a large contributor to the emissions of the global forest products industry. Furthermore, methane emissions are a large component of the global industry footprint because a large fraction of global production is disposed of in engineered anaerobic landfills after use. Green Resources' footprint does not include these emissions because, in the East African markets served by Green Resources' products, essentially all wood products are reused or burned for energy. Finally, because of the large role of plantations in the company's footprint, forestry management-related emissions are a larger component of the Green Resources' footprint compared to the importance of this component to the global industry.

[Insert Table 3]

Except for fire-related losses of forest carbon, the emissions are fairly evenly distributed along the value chain; therefore, the opportunities for reducing emissions are also fairly evenly distributed. Most of the emissions reductions within the direct control of Green Resources, however, appear to be related to manufacturing (i.e., consumption of fuels and electricity). The benefits of continued expansion of the plantations will likely be larger than the opportunities for reductions in the rest of the value chain for some time to come. In addition, a planned combined heat and power facility, which will use biomass for fuel, is expected to result in large avoided emissions since much of the electricity will displace coal-based electricity on the grid.

Most of the findings of this footprint are expected to be relevant to other companies involved in afforestation activities whose primary products are wood products and renewable energy. In such cases, until plantations are fully established, these carbon footprints are likely to be dominated by the large net removals of $\mathrm{CO}_{2}$ from the atmosphere that occur as a result of increasing land-based carbon stocks from a low initial level to a final level representing the average carbon stocks over the area of planted forest. The experience of Green Resources AS highlights the potential importance of events, like forest fires, that can cause catastrophic losses of forest carbon and have a large impact on the carbon footprints of forest-owning companies.

After plantations are established, the annual increases in land-based carbon stocks first diminish and then cease because, in the established forests, additions to land-based carbon due to forest growth are offset by carbon removals via harvesting. Thereafter, the greenhouse gas benefits associated with such enterprises are attributable to (a) keeping the land in forest, and (b) the use of the forest-derived products. The main products of Green Resource AS (wood products and renewable energy) will continue to produce benefits via long-term carbon storage and substitution for more greenhouse-gas alternatives in commerce even when the plantations are fully established. Although not estimated in this footprint, it may become useful at some point to also estimate the avoided emissions associated with using wood poles and lumber as substitutes for more greenhouse gas-intensive alternatives. These substitution effects can be large (e.g., see Miner, 2010).

The data in Table 3 for the global industry illustrate that in many situations, the end-of-life management of forest products is an important part of the overall carbon footprint of forest-based enterprises. This was not the case for Green Resources AS, but companies whose products are used in developed countries may have carbon footprints that more resemble the global footprint shown in the table, because in these countries, a fraction of used product is likely to be managed at end-of-life in ways having greenhouse gas implications. 


\section{Conclusions}

Green Resources AS is a forest-based company operating in East Africa where it is involved in afforestation activities and the production of wood products and renewable energy. The company's carbon footprints in 2008 and 2009 were calculated using the Forest Industry Carbon Assessment Tool (FICAT). The company was motivated to calculate its carbon footprint by a desire to identify potential liabilities and opportunities, to inform internal and external discussions on environmental sustainability, and to be an active participant in efforts to develop carbon footprint methodology.

In both 2008 and 2009, the company's afforestation activities dominated the footprint results, with afforestation-related net removals of $\mathrm{CO}_{2}$ from the atmosphere equaling 132,000 tons of $\mathrm{CO}_{2}$ in 2009. This was more than 17 times the total emissions from the company's value chain. The net removals in 2009 would have been 37\% larger were it not for a severe forest fire, highlighting the importance of forest management activities that reduce the likelihood and severity of such events.

Total value chain emissions in 2009 increased to 7,655 tons $\mathrm{CO}_{2}$ equivalents, compared to 5,974 tons of $\mathrm{CO}_{2}$ equivalents in 2008, primarily due to increased production. Emissions related to manufacturing, wood production, non-wood inputs, purchased electricity, and transport each amounted to approximately 1,000 to 2,000 tons of $\mathrm{CO}_{2}$ equivalents per year. Because the company's products are almost always recovered for other uses after being discarded, the company's footprint contains no emissions from product end-of-life.

The amounts of carbon expected to remain stored for at least 100 years in long-lived Green Resources' wood products are adequate to offset approximately one-quarter to one-third of the emissions from the company's value chain. In addition, the use of the charcoal manufactured by Green Resources AS avoids coal-related emissions equal to approximately one-quarter of the company's value chain emissions.

The company's carbon footprints suggests that an opportunity for improvement lies in increased production of low greenhouse-gas-intensity electricity produced from manufacturing residuals that are currently unused. The company plans to pursue this opportunity. It may also be possible to reduce emissions from forestry, manufacturing, and transport operations, but these reductions are unlikely to be as large as the benefits from additional renewable energy production, especially given expectations that the company's output of wood products will increase over time.

The Green Resources AS footprint reveals the carbon benefits of afforestation activities and the benefits associated with forest-based products produced from sustainably managed forests. Not considering afforestation benefits, the products manufactured by Green Resources AS currently offset and avoid societal emissions by an amount equal to over one-half of the company's value chain emissions. By keeping land in sustainably managed forest, managing the forest to reduce the likelihood and severity of fires and other disturbances, and producing low greenhouse-gas-intensity products like sawn wood and renewable energy, Green Resources AS, and other forest-based companies, can provide greenhouse gas mitigation benefits to society that complement, but are not dependent on, afforestation.

The Green Resources AS footprint provides an excellent example of the concepts embodied in IPCC's finding that "in the long term, a sustainable forest management strategy aimed at maintaining or increasing forest carbon stocks, while producing an annual sustained yield of timber, fibre or energy from the forest, will generate the largest sustained mitigation benefit" (IPCC, 2007b, p. 543).

\section{Acknowledgements}

The authors gratefully acknowledge the International Finance Corporation (IFC) of the World Bank Group and the Government of Finland for their support of the Forest Industry Carbon Assessment Tool. In particular, the authors thank Dwight O'Donnell and Anna Akhalkatsi of IFC for their efforts on this carbon footprint project. The authors also thank Hosea Elia and Jakob Sandven of Green Resources AS and David Elibariki of Sao Hill Industries for their assistance in assembling the needed information. The assistance of Anna Aviza of NCASI in preparing the manuscript is also gratefully acknowledged.

\section{References}

Carbon Disclosure Project (CDP). (2011). Carbon Disclosure Project: Supply Chain Report 2011. Retrieved March 13, 2010, from www.cdproject.net/CDPResults/CDP-2011-Supply-Chain-Report.pdf

Cherubini, F., Bird, N., Cowie, A., Jungmeier, G., Schlamadinger, B., \& Woess-Gallasch, S. (2009). Energy- and greenhouse gas-based LCA of biofuel and bioenergy systems: Key issues, ranges and recommendations. Resources, Conservation and Recycling, 53(8), 434-447. http:dx.doi.org/10.1016/j.resconrec.2009.03.013 
Clean Development Mechanism (CDM) Executive Board. (2006). Mitigation of methane emissions in the charcoal production of Plantar, Brazil: Version Number: 6.a; CDM Project Design Document. Clean Development Mechanism Executive Board.

Confederation of European Paper Industries (CEPI). (2007). Framework for the development of carbon footprints for paper and board products. Brussells: Confederation of European Paper Industries.

Green Resources AS (GRAS) (2011). http://www.greenresources.no/

Gustavsson, L., \& Sathre, R. (2006). Variability in energy and carbon dioxide balances of wood and concrete building materials. Building and Environment, 41(7), 940-951. http://dx.doi.org/10.1016/j.buildenv.2005.04.008

Heath, L., Maltby, V., Miner, R., Skog, K., Smith, J., Unwin, J., \& Upton, B. (2010). Greenhouse gas and carbon profile of the U.S. forest products industry value chain. Environmental Science and Technology, 44(10), 3999-4005. http:dx.doi.org/10.1021/es902723x.

Intergovernmental Panel on Climate Change (IPCC). (2006). 2006 IPCC guidelines for national greenhouse gas inventories. Hayama, Kanagawa, Japan: IPCC, c/o Institute for Global Environmental Strategies.

Intergovernmental Panel on Climate Change (IPCC). (2007a). Changes in atmospheric constituents and in radiative forcing. Chapter 2 in S. Solomon, D. Qin, M. Manning, Z. Chen, M. Marquis, K.B. Averyt, M.Tignor and H.L. Miller (Eds.), Climate change 2007: The physical science basis. Contribution of Working Group I to the Fourth Assessment Report of the Intergovernmental Panel on Climate Change. Cambridge, UK and New York: Cambridge University Press.

Intergovernmental Panel on Climate Change (IPCC). (2007b). Forestry. Chapter 9 in B. Metz, O.R. Davidson, P.R. Bosch, R. Dave, L.A. Meyer (Eds.), Climate change 2007- Mitigation. Contribution of Working Group III to the Fourth Assessment Report of the Intergovernmental Panel on Climate Change. Cambridge, UK and New York: Cambridge University Press.

International Finance Corporation/National Council for Air and Stream Improvement (IFC/NCASI). (2009). The Forest Industry Carbon Assessment Tool (FICAT). Retrieved June 10, 2010, from www.FICATModel.org

Miner, R. (2006). The 100-year method for forecasting carbon sequestration in forest products in use. Mitigation and Adaptation Strategies for Global Change. http:dx.doi.org/10.1007/s11027-006-4496-3.

Miner, R. (2010). Impact of the global forest industry on atmospheric greenhouse gases (FAO Forestry Paper 159). Rome: United Nations Food and Agriculture Organization (FAO).

National Council for Air and Stream Improvement, Inc. (NCASI) (2009). Model documentation for the Forest Industry Carbon Assessment Tool (FICAT). Research Triangle Park, NC: National Council for Air and Stream Improvement, Inc. Retrieved June 22, 2009, from www.FICATModel.org

Perez-Garcia, J., Lippke, B., Comnick, J., \& Manriquez, C. (2005). An assessment of carbon pools, storage, and wood products market substitution using life-cycle analysis results. Wood and Fiber Science, 37(CORRIM Special Issue), 140-148.

Salazar, J., \& Sowlati, T. (2008). A review of the life-cycle assessment of windows. Forest Products Journal, 58(10), 91-96.

Swiss Centre for Life Cycle Inventories. (2010). Ecoinvent lifecycle database. Dubendorf, Switzerland: Swiss Federal Laboratories for Materials Testing and Research.

United States Department of Energy (USDOE). (2010). U.S. life-cycle inventory database. Retrieved June 30, 2008, from http://www.nrel.gov/lci/database/default.asp

United States Environmental Protection Agency (USEPA). (2006). Solid waste management and greenhouse gases: A life-cycle assessment of emissions and sinks (3rd ed.). Washington DC: United States Environmental Protection Agency.

United States Environmental Protection Agency (USEPA). (2007). Sector collaborative on energy efficiency: Office building energy use profile. Background document prepared for the United States Environmental Protection Agency (USEPA) Sector Collaborative on Energy Efficiency. Washington DC: National Action Plan for Energy Efficiency, United States Environmental Protection Agency.

World Resources Institute/World Business Council for Sustainable Development (WRI/WBCSD). (2005). Mobile combustion CO2 emissions calculation tool for the GHG Protocol: Version 1.3. Retrieved from GHG Protocol: www.ghgprotocol.org 
Table 1. The ten elements of a carbon footprint of a forest-based activity used in FICAT

1. $\quad$ Carbon in forest ecosystems

Green Resources AS is developing plantations by afforestation of degraded grassland in Tanzania, Uganda, Mozambique, and Southern Sudan. Wood is also obtained from existing government-owned planted forests. All forestry operations are aligned with Forestry Stewardship Council procedures which guarantee sustainable management, thereby providing jobs to community, providing community services, conservation of natural forests and endangered species (flora and fauna), etc. Carbon stock changes were estimated for all lands from which Green Resources AS obtains wood and all lands planted to provide wood in the future.

2. Carbon in forest products

The products of Green Resources AS that store carbon include sawn timber and a number of value-added wood products (e.g., doors). The fate of this carbon during use and at end-of-life was estimated. In addition, the company produces charcoal.

3. Greenhouse gas emissions associated with forest product manufacturing facilities and offices

Industrial operations include all the activities involved in the saw mill at Sao Hill. The mill produces sawn timber, a number of value-added products (e.g., doors), and charcoal. Emissions included were from fuel consumption for generators, saw mill operations, and office locations in Sao Hill and elsewhere. Emissions from charcoal production at Sao Hill are also included.

4. Greenhouse gas emissions associated with producing wood

Fossil fuel is used in both the company's plantation forests as well as in existing planted forests owned by the government, which are supplying wood to Green Resources AS. The footprint here considered emissions derived from fuel consumption (harvesting equipment, tractors, and transport of staff/management team for the forest operations). Emissions included here were also from the burning of the government forest from which Sao Hill Industries harvests the wood.

5. Greenhouse gas emissions associated with producing other raw materials/fuels

Upstream emissions of chemicals used in the forest (fertilizers, pesticides, etc.) were included as were upstream emissions associated with fossil fuels and glues, varnishes, paints, and other products used in the carpentry sections.

6. Greenhouse gas emissions associated with purchased electricity, steam, and heat

Upstream emissions from electricity consumption in manufacturing operations and offices were included.

7. Transport-related greenhouse gas emissions

Emissions related to transport of raw materials and final products, as well as employees' travel, were included.

8. Emissions associated with product use

Emissions associated with using charcoal, sold by Green Resources AS as a fuel, were included.

9. Emissions associated with product end-of-life

It was determined that it was very unlikely that products would be landfilled at end-of-life. Instead, in the markets served by Green Resources AS, used products are likely to be recovered and reused for other purposes.

10. Avoided emissions

The charcoal product sold by Green Resources replaces coal at the industrial facility that uses it. The avoided coal-related emissions have been estimated.

This table lists the ten elements of the FICAT Carbon Footprint and explains how the Green Resources value chain can be described by these elements 
Table 2. The Green Resources AS carbon footprint: tons $\mathrm{CO}_{2}$ eq. per year

\begin{tabular}{|c|c|c|c|c|c|c|}
\hline \multirow[b]{2}{*}{ Element 1: Land-based carbon } & \multicolumn{3}{|c|}{2008} & \multicolumn{3}{|c|}{2009} \\
\hline & \multicolumn{3}{|c|}{$-125,000$} & \multicolumn{3}{|c|}{$-132,000$} \\
\hline Element 2: Carbon in product & \multicolumn{3}{|c|}{$-2,003$} & \multicolumn{3}{|c|}{$-2,260$} \\
\hline \multirow[t]{3}{*}{ Net emissions related to forest carbon } & \multicolumn{3}{|c|}{$-127,000$} & \multicolumn{3}{|c|}{$-134,000$} \\
\hline & \multicolumn{3}{|c|}{2008} & \multicolumn{3}{|c|}{2009} \\
\hline & Direct & Indirect & Total & Direct & Indirect & Total \\
\hline Element 3: Manufacturing & 1,068 & 0 & 1,068 & 2,118 & 0 & 2,118 \\
\hline Element 4: Wood production & 245 & 1,799 & 2,044 & 336 & 1,582 & 1,918 \\
\hline Element 5: Non-fibrous inputs & 0 & 832 & 832 & 0 & 1,170 & 1,170 \\
\hline Element 6: Purchased electricity & 0 & 1,025 & 1,025 & 0 & 1,033 & 1,033 \\
\hline Element 7: Transport & 694 & 308 & 1,002 & 784 & 607 & 1,391 \\
\hline Element 8: Product use & 0 & 3 & 3 & 0 & 25 & 25 \\
\hline Element 9: End-of-life & 0 & 0 & 0 & 0 & 0 & 0 \\
\hline \multirow[t]{3}{*}{$\begin{array}{l}\text { Total value chain emissions, not } \\
\text { including impacts on forest carbon }\end{array}$} & 2,007 & 3,967 & 5,974 & 3,238 & 4,417 & 7,655 \\
\hline & \multicolumn{3}{|c|}{2008} & \multicolumn{3}{|c|}{2009} \\
\hline & Direct & Indirect & Total & Direct & Indirect & Total \\
\hline Element 10: Avoided emissions & 0 & 212 & 212 & 0 & 1,821 & 1,821 \\
\hline
\end{tabular}

This table contains the results of the calculations to determine the carbon footprint of Green Resources AS

Table 3. Comparing the Green Resources AS carbon footprint to the footprint of the global forest products industry*

\begin{tabular}{|c|c|c|}
\hline \multirow[b]{2}{*}{ Emissions category } & \multicolumn{2}{|c|}{ Fraction of value chain emissions in each category } \\
\hline & Green Resources (2009) & Global forest products industry \\
\hline - Forest management-related emissions & $25 \%$ & $2 \%$ \\
\hline $\begin{array}{l}\text { - Upstream emissions associated with chemicals } \\
\text { and fossil fuels }\end{array}$ & $15 \%$ & $10 \%$ \\
\hline - Manufacturing-related emissions & $41 \%$ & $55 \%$ \\
\hline - Transport-related emissions & $18 \%$ & $6 \%$ \\
\hline - $\quad$ Product use-related emissions & $0.3 \%$ & $0 \%$ \\
\hline - End-of-life emissions & $0 \%$ & $27 \%$ \\
\hline - Net sequestration in forests & $-1,725 \%$ & $0 \%$ \\
\hline - Net sequestration in products & $-30 \%$ & $-48 \%$ \\
\hline
\end{tabular}

\footnotetext{
* Based on data in Miner (2010)
}

This table compares the Green Resources AS carbon footprint to the carbon footprint of the global forest products industry. 